\title{
The Prehistory of the Colombian Territory: the Results of the Italian Archaeological Investigation on the Checua Site (Municipality of Nemocón, Cundinamarca Department)
}

\author{
A. Minelli ${ }^{1}$, M. Cozzolino ${ }^{1}$, A. Di Nucci ${ }^{1}$, S. Guglielmi ${ }^{1}$, M. Giannantonio, \\ D. D'Amore', E. Pittoni' ${ }^{2}$ A.M. Groot ${ }^{3}$ \\ ${ }^{1}$ Faculty of Human and Social Sciences, University of Molise, Via Mazzini 8, 86170 Isernia, Italy. E-mail: antonella.minelli@unimol.it \\ ${ }^{2}$ Collaborator University of Cagliari and Archaeological Superintendence of Cagliari \\ ${ }^{3}$ Faculty of Human Sciences, National University of Colombia, Carrera 30 N.45-03 - Bogotà.
}

KEY WORDS: ERT surveys, prehistoric investigations, first Colombian population.

\section{Introduction}

This paper shows the results of the archaeological investigations on the Checua site, located in the high plain of the Bogotà Savanna, within the scientific research program of the Italian team, supported by the Italian Ministry of the Foreign Affairs (Archaeological and Anthropological Missions Program), finalized to give a contribution, through the application of innovative methodologies, on the most ancient human presence on the Colombian territory.

The patterns of human distribution and subsistence practices across the South American continent in the Late Pleistocene and the first Holocene periods could have been influenced by the changing climate and the resources structures.

The Pacific or Atlantic coastlines, deltas, wetlands and the major rivers favoured the migration of the people along the coasts and from the south portion of the continents laterally into the interior.Various wetland habitats in deltas and along major coastal rivers may have served as primary areas of initial adaptation and movement into higher river valleys (e.g., Magdalena) of the Andean mountains and adjacent plains of Colombia between 15.000 and 12.000 years ago (Dillehay, 1999).

The study of the Colombian prehistory had the contribution of G. Correal and T.Van der Hammen that have been documented archaeological evidences dated back from 12.500 years BP: the El Abra site (Correal et al., 1970), a series of rocky shelters located in the Municipality of Tocancipà, the Tibitò site (Correal and Moanack, 1980), with a dating between 11.000 and 10.000 years $B P$, the rocky shelters of Tequendama (Correal and Van der Hammen, 1977), in the Municipality of Soacha, dated between 10.000 and 8.500 years $B P$, the Aquazuque area, in the Municipality of Soacha, dated between 5.000 and 3.000 years BP (Correal, 1996) and finally the Vistahermosa site, in the Municipality of Mosquera, dated back to 3.000 years BP (Correal, 1987).

In the High Valley of the River Checua, from 1960, several archaeological studies have been realized, documenting evidences of the human presence dated to more than 9.000 years BP.The most representative sites of this region, dated back to $9.000-3.000$ years $B P$, might be interpreted as an evidence of the transition among life strategies of hunting-gathering and the beginning of stable settlements: Nemocón IV; Checua I,II; Rasgatá;Alto Checua I,II,III; Piedra Pintada (Correal, 1979; Groot, 1992).

\section{Materials and Methods}

Considering the importance of the mentioned archaeological sites it was planned to apply some geophysical instruments to verify the archaeological potentialities of the interested areas and to acquire indications on the possibility to realize systematic excavations.

Different factors have been considered in the planning of the geophysical interventions based on the preceding studies (Groot, 1992), that analyzed the logistic and environmental conditions, the characterization of the geological deposits and the depth of the archaeological evidences. In order to speed up the data acquisition it was considered a good compromise to use the ERT survey (Cammarano et al., 1997). The survey involves the experimental determination of a physical parameter called electrical resistivity which indicates the ability of bodies to let through by electric currents. Data are represented in the form of maps of resistivity values in which the planimetric variation in depth of the electrical parameter is highlighted by isolines. The 3D matrix of data on the volume of the explored soil was processed using the algorithm of 3D electrical resistivity tomography (Mauriello and Patella, 1999) in order to obtain a three-dimensional reconstruction of the electrical resistivity. 
The application of the ERT (Electrical Resistivity Tomography) surveys on the Checua site gave the clear indications to plan systematic excavation interventions. The ERT surveys have been carried out on the top of a small hill in three areas, located near the excavations realized by A. Groot of the National University of Colombia in 1991 (Groot, 1992). The measuring grid and the profiles were spaced with different variables depending from the proximity to the top of the hill. It have been acquired around 48.000 resistivity measurements. The vertical sections obtained have been correlated each other for getting a thin three-dimensional volume of $8 \mathrm{~m}$ in depth (Fig. 1), from which it has been possible to extrapolate the horizontal sections relative to different depths.

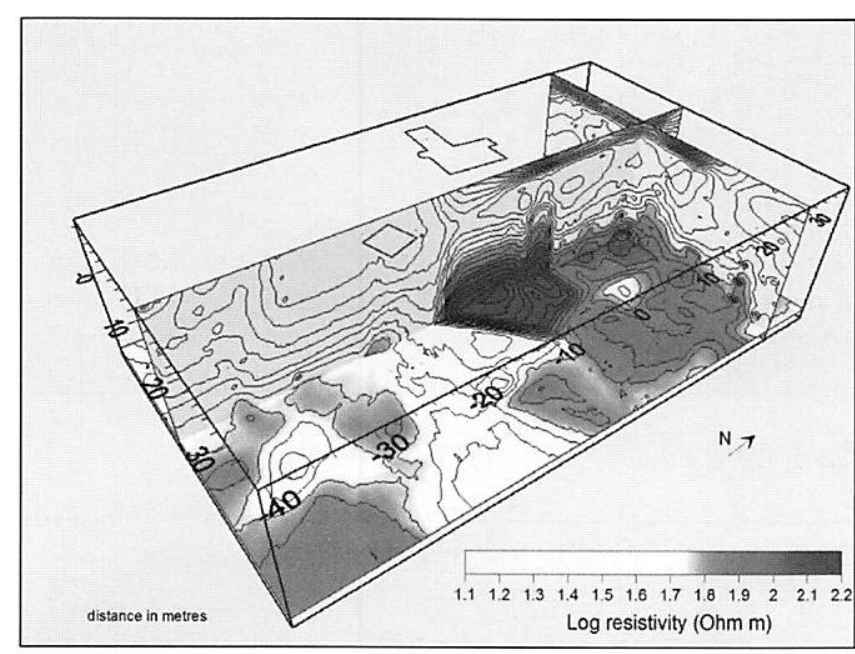

Fig. 1. ERT survey results: reconstruction of $3 D$ volume.

The map refers the presence of a high resistivity substratum in sandstone and a superficial low resistivity level in clay interrupted by an anomalous resistivity distribution corresponding to the top of the hill, where the archaeological evidences are more frequent.

Figure 2 shows the resistivity map at $1 \mathrm{~m}$ in depth and refers the presence of an anomalous quadrangular nucleo with medium resistivity values in the West area. The same situation has been recorded in the area located more at East.Very interesting is the anomalous nucleo with high resistivity values present in the Northwest of the investigated area. In the South part of the zone the resistivity values are uniform probably because of the presence of modern interventions. Considering the results of the ERT surveys, during archaeological investigations carried out in 2010 , three excavation areas were opened (Fig. 2): the first one (A) to verify the potentialities of the stratigraphic sequence in the Northeast part of the hill, the second one $(B)$ to verify the presence of the anomalous nucleo at medium resistivity and the last one (C) to individuate the recorded high resistivity corresponding to the sandstone blocks of a thickness of $0.3 \mathrm{~m}$ between the US2 and US3.This evidence is probably related to an ancient human intervention in the exploitation of the life settlements. The ERT surveys have recorded a low electrical resistivity beneath $2 \mathrm{~m}$ in depth evidencing the probability that the archaeological materials are located in the superficial strata (Figg.1-2).

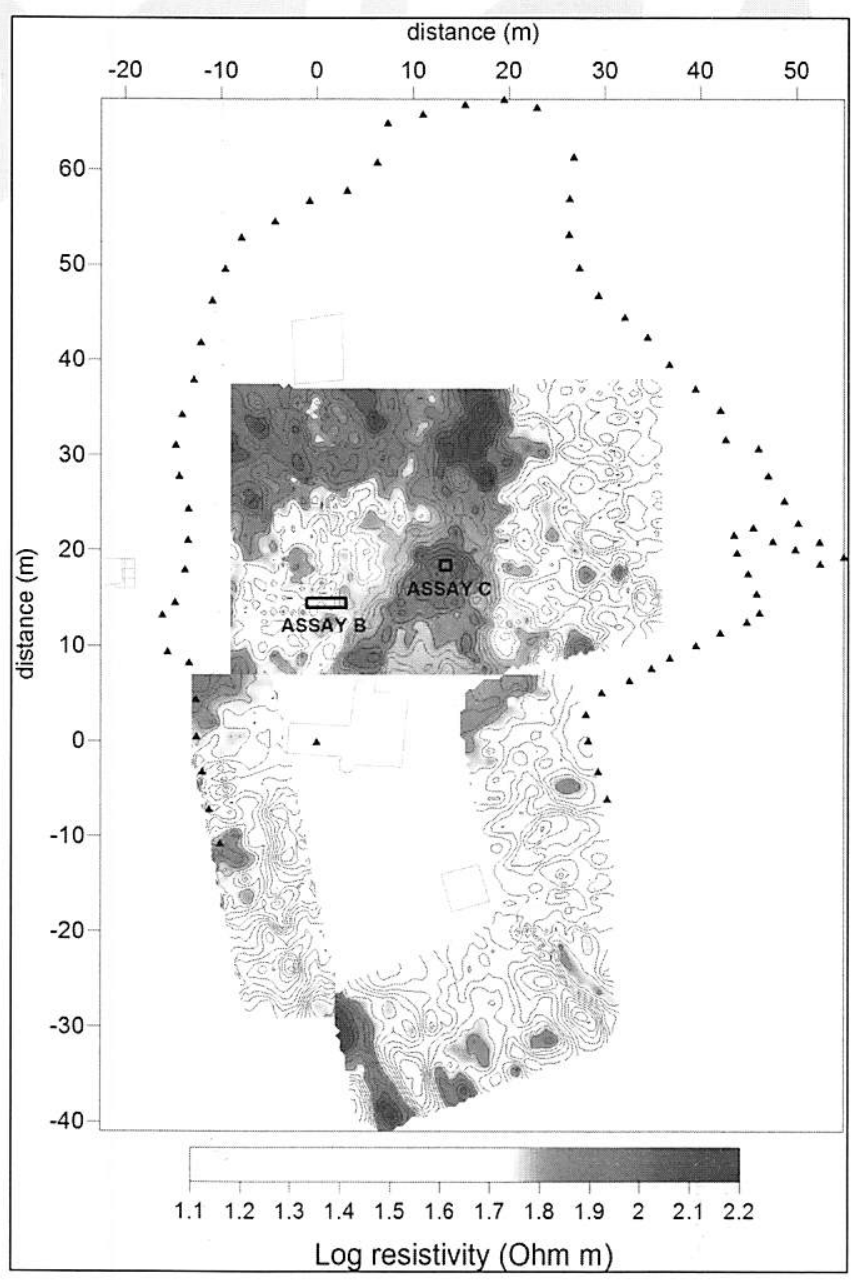

Fig. 2. Resistivity map at $1 \mathrm{~m}$ in depth and localization of the three excavated areas.

\section{Results: the Checua site}

The Checua site, before the Italian intervention, was known for the archaeological investigations carried out in 1991 (Groot, 1992).

The physiography of the area is characterized by a synclinal structure named "Checua-Lenguazaque", in which the river Checua and the surrounding mountains define two geological and geomorphological sectors: the river plain strongly interested by erosive agents and the mountains with altitudes that vary between $2700 \mathrm{~m}$ and $3200 \mathrm{~m}$ on the sea level, with cold and humid climate, and altitudes between $2600 \mathrm{~m}$ and $2900 \mathrm{~m}$ on the sea level, with cold and dry climate. The archaeological site of Checua is located on the limit between the river plain and the north-east slope of the hill. The human groups that settled in this area chose the highest part of the hill that rises about $15 \mathrm{~m}$ above the river plain level. The area extends for about $300 \mathrm{~m}^{2}$.

The excavation surveys carried out in November 2010 permitted to reconstruct a stratigraphic sequence of 7 levels that are approximately dated by the radiocarbon method (Laboratory of CEDAD, Lecce, Italy) on a gasteropod fragment and samples of coals from 3.000/3.500 years BP at the top, to 5.837 years BP (US3) and to 6.461 years BP (US4), until to 8.500 years BP at the 
base (US5-7) (Fig. 3). Four living-floors are almost achieved, very rich in palaeontological and palaeoethnological remains, burials and human rests, the quantity of which increases from the older archaeosurface to the younger one.

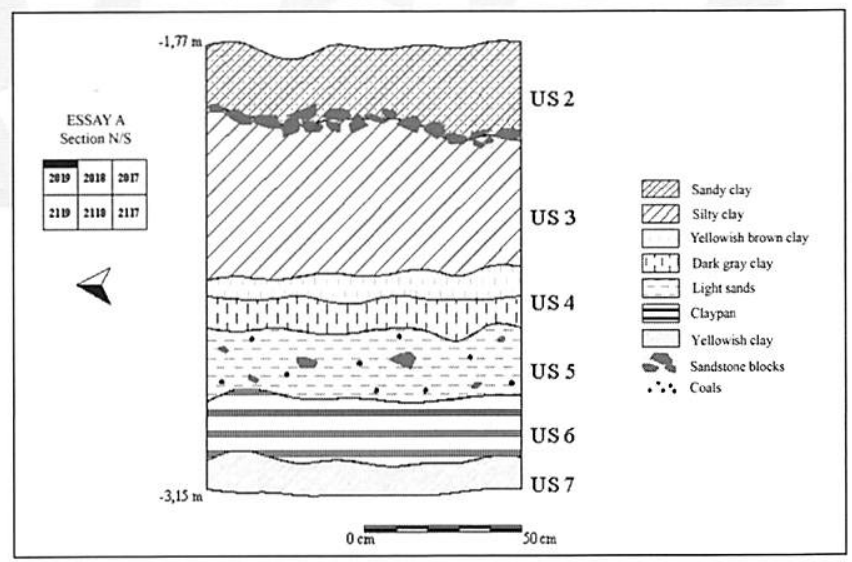

Fig. 3. Stratigraphic sequence of the excavated area.

A preliminary palaeontological study has been carried out on the total amount (most of 500 skeletal elements) of the animal bones and it has documented a significant presence of micro and macromammals. Most of the species identified have been described previously in Tequendama, El Abra and Nemocón IV sites (Correal et al., 1970; 1977; Correal, 1979 ) and they can be associated to Cavia porcellus (Guinea pig), typical of the semiarid climate, just domesticated in the El Abra site (Correal et al., 1970) and well represented in Checua, in the recent layers. Moreover, there are few skeletal fragments of the Sylvilagus sp. and the Sigmodon sp. The macromammals are represented by the deers of specimens Odocoileus virginianus that constitutes the most documented taxon in the ancient layer and less recorded, in comparison with the guinea pig, in the recent ones. Carnivores are attested from a third phalange of Felidae, just identified in other sites of the same period (Correal et al., 1970, 1977; Correal, 1979). The archaeozoological analysis documented a high fragmentation of the bones related essentially to the human interventions and cutmarks compatible with butchering and disarticulation activities.

The human rests belong to 4 individuals in single burials in primary deposition, respectively coming from the US2,3,4 in the essay $A(I 1,2,3)$ (Fig. 4), and from the essay $B(14)$. The shape of the burials is generally ovoidal or elliptical, covered by small and medium unworked sandstones. The exception is given for the 14 that is buried without covering, testifying maybe a change in the burial modalities in a more recent period.

The detailed anthropological study refers that the individuals are represented by 3 sub-adults respectively of $4-5$ years for $11,2-3$ years for 12 and 8 years for 13 . The individual 4 is an adult but its bad state of preservation didn't make possible the determination of the age.

The physical description of the skulls and skeletons and their comparisons with other early American skeletons

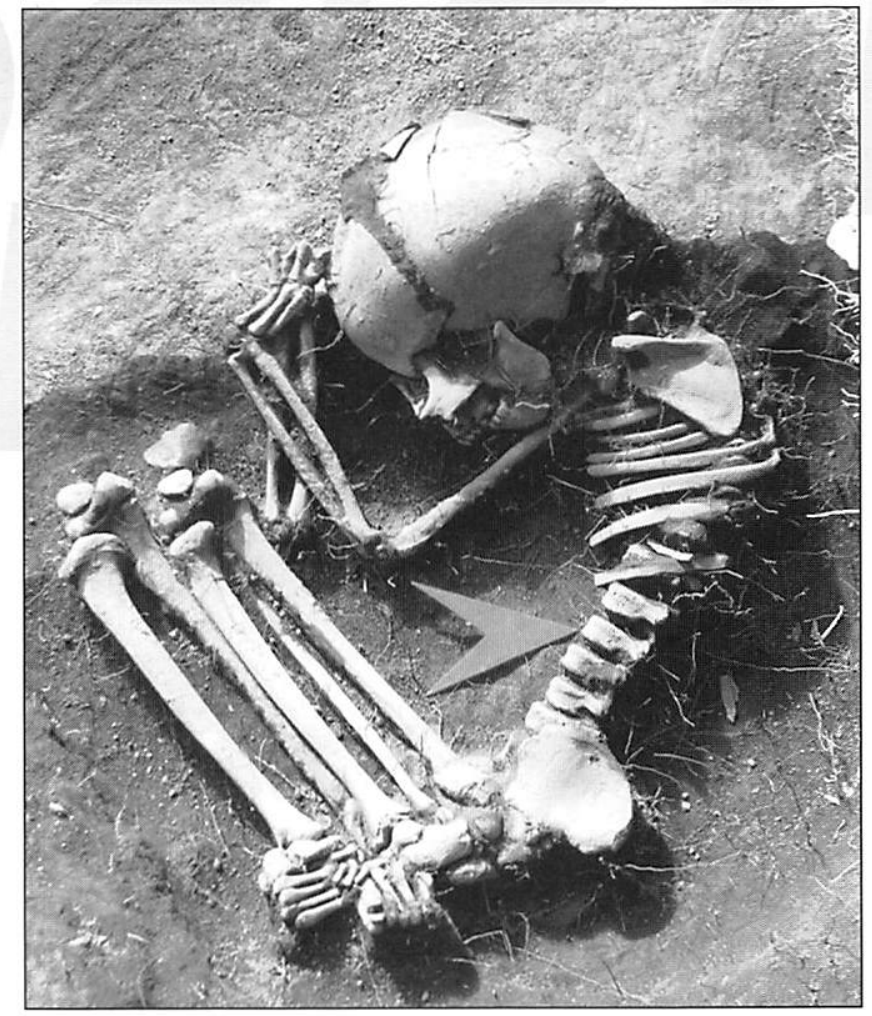

Fig. 4. Burial of 13 , male sub-adult of 8 years old.

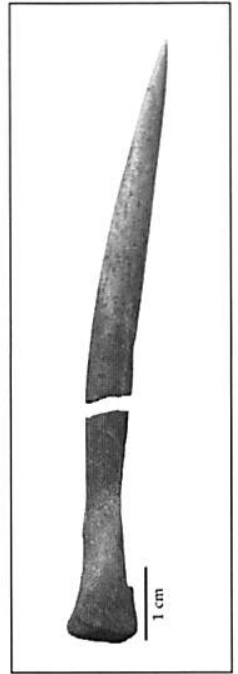

Fig. 5. Bone artefact.

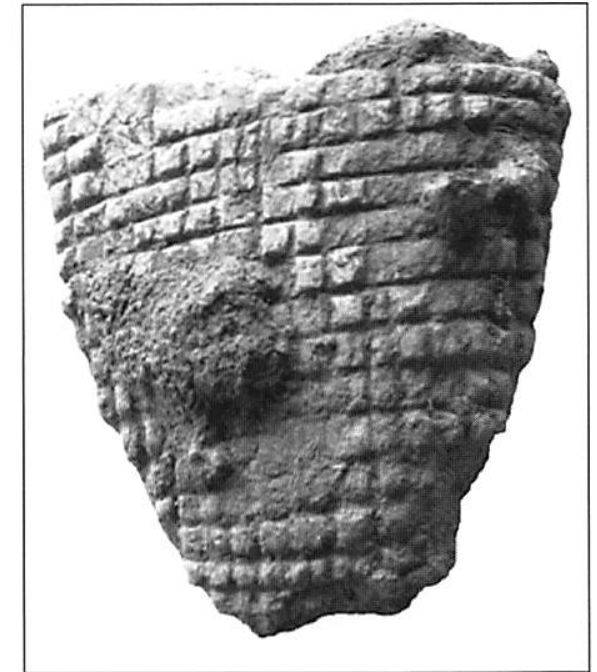

Fig. 6. Geometric artefact with a regular grid and an abrasive relief associated to the female burial (14). study. Anyway, the evidences of the extreme molar wears and other mandibular characteristics point to a tough and hard diet, as may be expected in groups of hunter-gatherers (Dillehay, 1999).

The recorded frequency of sub-adults individuals testifies a high infant-mortality index.

In the record of the material culture it has been achieved an high concentration of lithic finds. The lithic tools, obtained by exploiting the local raw material in sandstone and chert, show a significant typological percentages of unretouched flakes, basically setting to the "Abrian" technique (Correal et al., 1970). Other types of tools, 
present in low percentages and in the recent layers (mainly in the US2), are side-scrapers, end-scrapers, stone projectile points, blades, polishing instruments and bone points, that could have served for both wood-working and hide scraping industries, apart the bone artefacts, which requirement for multipurpose blanks is connected to the hunting-gathering activities (Fig. 5).

In the set of the material implements coming from the upper layers (US2) it could be add a particular geometric artefact with a regular grid and an abrasive relief (Fig. 6). Its functional use has been interpreted, comparing it with similar examples known in the Colombian areas, to grind the fiber plants, admitting a probable orientation of the human groups towards the horticulture (Dillehay, 1999). Its association to the burial of the individual adult, of female sex, enriches the cultural significance the context in terms of the social identification of the individual roles in the group.

Moreover the discovery of a bola or boleadora, in sandstone material, which appears in South America about 12.500 years ago at Monte Verde and between 11.500 years ago at others sites in eastern Brazil and in the southern half of the continent (Hernandez, 2002), can support the hypothesis that the new cultural evidences could be a consequence closely connected with the logical adaptive response to given environmental conditions.

\section{Discussion}

On the high plain of Bogotà Savanna a clear relation between the changing environment, human population and cultures can be established; the Checua site can provide the information about this association thanks to the different evidences put in light in the recorded layers of the stratigraphic sequence of the excavated areas.

Considering the chronology associated to the stratigraphic units from the base (8.200 BP) to the top (3.000 BP), it's possible to give a first and preliminary sketch of environmental life strategies of the human groups that lived in the Checua area in according to similar known evidences of the high plain of Bogotà (El Abra,Tequendama, Nemocón IV sites).

As regarding as the other sites of the Bogotà Savanna it's possible to suggest that during the last cold phase of the Last Glacial, the El Abra stadial (ca. 11.000-10.000 BP), relatively specialized deer hunters lived permanently or seasonally in the area, exploiting the abundant game of the uppermost zone of the Andean forest and the subparamo, settling in the open-air sites and in the rocky shelters (e.g. Nemocón IV). At the beginning of the Holocene (ca. 10.000 BP) the tree line moved far up the mountain slopes and the new environment consisted of dominating closer forest vegetation and probably a smaller deer population. Part of the equipment of the more specialized hunters indicates an importance of wood-working besides the stone-working, to hunter the deer, to capture small rodents, gatherer gasteropods and probably also roots and fruits. Around 5.000 BP the climate became considerably drier and reduced also the game animals. Around 3.000 BP the average annual temperature decreased slightly and the effective precipitation became higher leading to the formation of ponds and an increase of open marshes; water thus becoming more abundant in the area. The combined evidence from tools (bone artefacts, bolas, "mortar"), the faunal wastes (predominance of the Cavia in comparison to deer remains) and the burials data indicates that the adaptation to a drier climate and to a reduced vegetation led from a relatively specialized hunting culture to a somewhat more varied, partly hunting-domesticating animals and partly horticultural-agricultural way of life (Dillehay, 1999).

Future researches and detailed studies can be provide further information.

\section{References}

Cammarano F., Mauriello P., Patella D., Piro S. 1997. Integrated geophysical methods for archaeological prospecting. In: Volcanism and archaeology in Mediterranean sea: 7-34.

Correal Urrego G. 1979. Investigaciones arqueológicas en los abrigos de Nemocón y Sueva. Fundación de Investigaciones Arqueológicas Nacionales. Bogotá.

Correal Urrego G. 1987. Excavaciones arqueológicas en Mosquera. Arqueologia. No. 3. Revista de estudiantes de Antropología. Universidad Nacional de Colombia, 1:13-17.

Correal Urrego, G., 1996.Aguazuque I: un sitio preceramico tardio en la Sabana de Bogota. In: Boletin de Arqueologia, Fundacion de Investigaciones arqueológicas nacionales, Bogotá, 1: 3-24.

Correal Urrego G.,Van der Hammen T., Lerman, L. C., 1970. Artefactos liticos de abrigos rocosos en El Abra, Colombia. Revista Colombiana de Antropologia, 14: 9-53.

Correal Urrego G.,Van der Hammen T. 1977. Investigociones arqueológicas en los abrigos del Tequendama. Banco Popular. Bogotá.

Correal Urrego G., Moanack G.,1980. El sitio arqueologico Tibitò 1. Sociedad Arqueologica de Colombia. Bogotá.

Dillehay T.D. 1999. The Late Pleistocene culture of South America. Evol.Anthropol., 7,6: 206-216.

Groot A. M. 1992. Checua: una secuencia cultural entre 8.500 y 3.000 años antes del presente. Fundación de Investigaciones Arqueológicas Nacionales. Bogotá.

Hernandez J.V. 2002. Hondas y boleadoras en la America hispana. In:Anales del Museo de America, Madrid: 113-136.

Mauriello P., Patella D. 1999. Resistivity anomaly imaging by probability tomography. Geophys. Prospect. 47:411-429. 